Article

\title{
Harnessing Visibility and Invisibility through Arts Practices: Ethnographic Case Studies with Migrant Performers in Belgium
}

\author{
Shannon Damery * and Elsa Mescoli * \\ CEDEM-Centre for Ethnic and Migration Studies, Faculty of Social Sciences, University of Liege, Bâtiment 31 \\ Boîte 24 Quartier Agora-Place des Orateurs, 34000 Liège, Belgium \\ * Correspondence: Shannon.Damery@uliege.be (S.D.); E.Mescoli@uliege.be (E.M.)
}

Received: 13 February 2019; Accepted: 1 April 2019; Published: 4 April 2019

check for updates

\begin{abstract}
This paper endeavors to understand the role of arts in migration-related issues by offering insights into the different ways in which artistic practices can be used by migrants and investigating migrants' differing objectives in participating in the arts. Through the exploration of the initiatives of undocumented and refugee migrants involved in artistic groups in Belgium, this paper compares the motivations of the performers and concludes that art can operate as an empowering tool for migrants as it constitutes a space for agency, notwithstanding the specific scope of which it is contextually charged. It allows migrants to render themselves visible or invisible, depending on their contrasting motivations. The creative productions of the first group, composed by members of "La Voix des sans papiers de Liège", a collective of undocumented migrants, corresponds to an explicit effort of political engagement in the local context. The other examples are of undocumented and refugee artists joining musical groups with no specific aim of promoting the cause of undocumented and refugee persons. The choice to be involved in such groups highlights their desire to be, in some ways, invisible and anonymous while participating in this collective of artists. Through these examples, we see that art offers opportunities for migrants to actively participate in the socio-cultural and political environment in which they reside and to claim various forms of official and unofficial belonging whether it occurs through visibility or invisibility.
\end{abstract}

Keywords: arts; migration; Belgium

\section{Introduction}

The arts are one of the most accessible conduits through which migrants may find a sense of community belonging, even when not granted any kind of official acceptance or citizenship. Art can be used "to assert dignity and claim national membership" (DiMaggio and Fernández-Kelly 2015, p. 1236). It can be a way to increase 'visibility', raise awareness about a certain situation, further political aims, or to allow one to seamlessly fit into a community and find group belonging when one has no other aim than to become 'invisible'. In this article, we use mainly anthropological and sociological tools (both in terms of methodology and literature) to illustrate what was learned from case studies in arts groups in two urban areas in Belgium. We show how arts practices have been used by migrants to achieve the same aim, that of belonging in Belgium, but in two very different ways. In one case, undocumented migrants claim their right to be in Belgium by promoting their cause and making themselves visible through arts practices, and in the other cases, undocumented migrants and refugees use the arts as a way of blurring boundaries in order to shift their status as 'others' and obtain unofficial belonging in music groups.

As $\mathrm{O}^{\prime}$ Neill (2008) argues, there is tension between the discourse excluding migrants through criminalization, detention, deportation and control of borders, and the discourse that speaks of human 
rights, responsibilities and possibilities for multi-cultural citizenship. This tension is reflected in the fact that, generally in the media, asylum seekers and refugees are represented by other parties instead of being given the space to represent themselves. Performative arts-based work counters this misrecognition, thus becoming political. The study of these practices through collaborative research methods permits the fostering of mutuality among the researcher and his or her research participants (O'Neill 2008) and highlights the agency of the latter. Migrants have developed alternative and creative strategies for political action because they are excluded from formal means of political participation, such as elections, and from almost all kinds of political decision-making processes (Salzbrunn 2014). Migrants' artistic representations of their own lived experiences can be transformative by providing a conduit for recognition and by allowing migrants to act in a "socially significant way," regardless of their legal status, which May (2013) asserts is key to belonging. Street (2003) analysis of the link between politics and music underlines the ability of music to rally people together and stir an emotional collective response. Music has been used as a tool by governments, political actors, and various groups with political agendas to garner support for causes, but Street also points out that it is the very power of music to mobilize people that makes it a tool to be feared by restrictive regimes (Street 2003, p. 117). The qualities of music that grant it this utility/power are its accessibility, communal aspects (often it is performed in groups and people work together toward a common aim) (May 2013), and the way it can tap into memory and emotions (May 2013; Elias et al. 2011; Tacchi 1998). It is these conditions that can both mobilize people to act politically or to feel a sense of belonging to a group, with or without political aims.

While much of the literature from cultural studies, sociology, and anthropology that investigates the role of art as a tool for belonging or political expression is focused on music, we argue that many of the assertions about music in this area can be applied to numerous collective art forms. Various collective art forms share the same qualities as those mentioned above with regard to music. This is not to say that music does not have unique qualities, but in the cases explored here we find that various art forms can foster political action and belonging.

Undoubtedly, the arts, in their accessibility, make certain types of political expression possible for disadvantaged groups who have fewer opportunities to take political action-in this case, asylum seekers and refugees (Martiniello and Lafleur 2008, p. 1207)—, but the arts are also a pathway to other types of less visible belonging. As Baily and Collyer state, "the circumstances of migration are likely to have a profound effect on how music fits into the migrant experience" (Baily and Collyer 2006, p. 172). The arts can have different meanings and impacts on a person's life depending on how they have migrated and what their aims are in their new place of residence. Often times, the chances to blend in through participation in arts groups are not as numerous as the opportunities to speak out. However, it is the interpretation of arts practices as either political or not that may impact the artists' desires to be seen and heard or to remain an inconspicuous part of a group. Martiniello and Lafleur (2010, p. 214) state, " ... the specialists of Cultural Studies tend to exaggerate the political dimension of art and culture in general. For many of them, nothing can be without political relevance". Rose, on the other hand, cautions against overlooking the political relevance of artistic production that does not have an explicit political message. She urges audiences to consider the many facets of the various contexts surrounding the production of the art.

Rap in its infancy was considered to be 'party music' with no political significance or aim, but as it evolved it took forms that were explicitly/obviously political. [ ... ] to dismiss rappers who do not choose so-called 'political' subjects as 'having no politically resistive meaning' requires ignoring the complex web of institutional policing to which all rappers are subject. (Rose 1991, p. 276)

What matters in the determination of which is art is political, and indeed its meaning overall, is the intention of the artist, the reception of the audience, the sociocultural and historical context, and a host of other factors (Roy 2010; Becker 1982). This often makes it difficult to determine how / whether art is political. 


\section{Methodology}

We gathered the material presented in this article mainly through participant observation. Emerson et al. describe participant observation as "establishing a place in some natural setting on a relatively long-term basis in order to investigate, experience and represent the social life and social processes that occur in that setting ..." (Emerson et al. 2001, p. 353). This research method, for which we took an anthropological approach, enabled us to comply with the ethical concerns encountered when studying issues related to vulnerable populations (Harrell-Bond 1986). In fact, it is often the case that interrogating individuals who have undergone ${ }^{1}$ an interview process that led to legitimating or, conversely, de-legitimating their presence in Belgium, through granting or denying a regular legal status, was often inappropriate. In situations where this was not the case and it was deemed that due to their regularized situation or their keen interest in being interviewed, interlocutors were interviewed in order to supplement the material gathered from participation ${ }^{2}$. Collaboration ${ }^{3}$ in the artistic practices of interlocutors produced knowledge in a process that allowed for a more sensuous understanding where it was crucial to share life experiences in a mutual exchange between the researchers and their research participants. All participants, including the researchers, were thus equal parts of a creative process that combined each one's thoughts and narratives. In this type of collaboration, artistic products are not ready-made objects of analysis, but rather the results of a shared process that involves the research participants and the researcher himself/herself in this production of knowledge ( $\mathrm{O}^{\prime} \mathrm{Neill}$ 2008). May (2013) explains that "cultural belongings are experienced in an embodied manner, for example when singing a national anthem, wearing a familiar piece of clothing or eating a national dish" (p. 131) and Pink (2009) advises researchers to have experiences that are as similar as possible to those of one's participants. The researchers personally engaged in the artistic work of the participants in order to get a better/different understanding of their sense of belonging. This level of collaboration allowed the researchers to uncover the differing aims and motivations of the interlocutors through the process of creating an artistic product.

Concerning the artistic practices of undocumented migrants in Liege that are analyzed in the next section, they have been observed within the framework of a research project focused on public opinion on migrants (already mentioned above, see footnote 4) which also included the study of the mobilization activities of migrants themselves. To implement this study, the researcher participated in several artistic workshops, and in particular in the writing workshops that led to several theatre representations and exhibitions, as well as in a theatre workshop held at the Theatre of Liege. As we will see in detail below, the analysis of the collected-and co-produced-material shows how the arts have potential effects on the local population. The research conducted in Brussels was part of a PhD project in which the researcher endeavored to understand young migrants' homemaking strategies and sense of belonging in the city. The research was carried out by attending rehearsals, singing and playing drums with the group, and performing at various events. In the instances when the researcher was not participating in arts practices, the researcher was participating in demonstrations and manifestations that were a part of the wider research aim.

\footnotetext{
Or that are still undergoing, as far as asylum seekers are concerned.

Informed consent was always obtained prior to interviews and questions concerning participants' past were not asked in order to avoid re-traumatization.

3 In fact, some members of the group also participated in preparing the researcher's intervention in an artistic and scientific event by recording and editing a video showing some of their artistic workshops. See https:/ / traverses.hypotheses.org/ (accessed on 17 January 2019), communication by Bertholet et al. (2018).
} 


\section{Arts to Be Visible}

\subsection{Liege, $A$ "Welcoming City"}

Former capital of an ecclesiastic principality and trigger site of successive democratic revolutions, the thousand-year-old city of Liege was characterized by an economic growth in the 19th century due to the expansion of the coal industry and the development of armory and glass working ${ }^{4}$. This fact, together with a process of progressive urbanization and development of modern infrastructures, attracted a labor workforce from abroad. After the recession that came when the coal mines were forced to close starting from the 1950s, new sectors of economy and services developed. The province of Liege counts 1,105,733 inhabitants, and the city 196,685 on the 1st January, $2019^{5}$. In the last available analysis of the composition of the population realized by the municipality in 2015, 37,377 inhabitants were registered with foreign nationality-25.5\% of that year's population ${ }^{6}$. While some scholars define Liege as a "post-migration city" (Martiniello 2011) due to its migration history, others also underline that this make-up is still continuously re-defined by human mobility (Bousetta et al. 2018, pp. 71-72). As a consequence, space for migrants and cultural diversity is still the object of debates (Bousetta et al. 2018, p. 72) that intersect the local environment and the state context. The enduring restriction of migration policies, also resulting in a process of the securitization of migration that includes repeated state actions against irregular migrants (such as raids, imprisonments and evictions), puts constraints on the local governance of migration issues. On the one hand, this process has resulted in an increase in the number of undocumented migrants since the last regularization program held in 2009 (Bousetta et al. 2018, p. 81) and, on the other hand, it undermines the possibilities of challenging this situation. Within this overall context, where public opinion and related actions are polarized-in the sense that people deal with migration issues either through civic engagement to support them, or through overt opposition ${ }^{7}$ - the city of Liege, with its main institutional, political, social and cultural actors still tries to position itself as relatively open to migrants. Recently labeled as a "welcoming city" (ville hospitalière), following a citizens' campaign supported by a Belgian $\mathrm{NGO}^{8}$, Liege engaged in adapting its actions and services to the needs and claims of migrants living in its territory. This approach is also supposed to concern undocumented migrants, and this means that, officially, the local government promotes a general climate of "tolerance" in addition to guaranteeing certain rights 9.

\subsection{La Voix des Sans-Papiers de Liège}

The history of the occupation of public buildings (or churches) by undocumented migrants in the city of Liege-and thus of these individuals' presence in the city-goes back at least to the years that preceded two main regularization programs, which occurred in 1999 and 2009. As far as the collective "La Voix des Sans-Papiers de Liège" (VSP from now on) is concerned, it was created in 2015 and grew from the occupation of an uninhabited public building. The building was occupied by a small group of sub-Saharan migrants whose irregular situation was the result of the rejection of their asylum demand in Belgium or the expiration of their visa (for tourism or education). At first, the needs of the collective consisted of securing accommodation for people—women, men and children of all ages—who were

4 See the municipality official website at: https://www.liege.be/en/discover/tourism/discover-liege/history-of-liege (accessed on 16 March 2019).

5 See the Belgian government official statistics available at https:/ / www.ibz.rrn.fgov.be/fileadmin/user_upload/fr/pop/ statistiques/population-bevolking-20190101.pdf (accessed on 16 March 2019).

6 See https://www.liege.be/fr/vie-communale/administration/liege-en-chiffres/tableaux-de-bord-population/tableaude-bord-population-2015.pdf (accessed on 16 March 2019).

7 Such process is the object of a recent research project funded by the Belgian Federal Science Policy Office (BELSPO) and aimed at studying the "Public opinion, mobilisations and policies concerning asylum seekers and refugees in anti-immigrants times (Europe and Belgium)" (PUMOMIG). The ethnographic material presented in this paper and concerning migrants' action in the city of Liege has been collected within the framework of this project.

8 See the website of the campaign at https:/ / www.communehospitaliere.be/ (accessed on 17 January 2019).

9 Among them are the rights of "urgent medical care" (aide médicale urgente) and education. 
living on the streets. The following quote by one of the founders of the initiative, now residing legally in Belgium after his regularization through family reunification, narrates the beginning of the initiative and its initial aims:

"Sans-papiers were around ten [... ] we occupied the building, it is there [in Sclessin, a neighbourhood of Liege] that the occupation started [... ]. During the first days the soutiens ${ }^{10}$ managed to bring food, volunteers connected the water, they set electricity on, they took boilers, they did all that was needed to occupy the building".

(Salim, recorded on 30 January 2018) ${ }^{11}$

In time, the group grew in number and it moved to another public building which used to be a local school (see Figure 1). This movement, that geographically brought the collective closer to the city centre, also corresponded to a political change. In fact, from this moment on, the interactions with public authorities and the civil society intensified and also led to some economic support (beside the fact that the occupation was locally accepted ${ }^{12}$. It was then possible to set other priorities and push the aims of the collective forward:

"After a month [ ... ] because if we want to create an effective [social] movement we have to organize meetings, [ . . ] w we made the meetings of the collective. [ ... ] we were united for a cause. [... ] [so that] the sans-papiers as such could assume their status and claim it high and loud and say: 'I am a sans-papiers', because it is not a crime. [ . . ] people hide themselves because they are sans-papiers. [ ... ] but it's the system that makes you a sans-papiers, and if you really want to fight against this, you have first to start diagnosing [diagnostiquer in French] yourself". (Salim, recorded on 30 January 2018)

These words are similar to De Genova (2002) theory about the legal production of illegality, and how people begin to claim their rights by re-appropriating "illegal status". Such rights consist of the authorization to live in Belgium and access to the civic liberties that are associated with this.

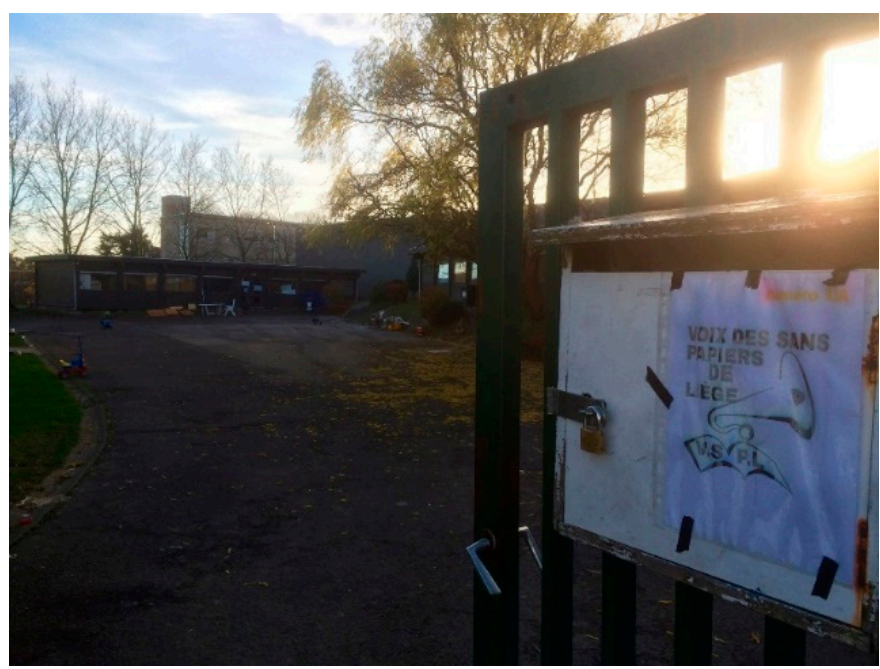

Figure 1. The buildings inhabited by the members of the collective $\subset$ La Voix des Sans-Papiers de Liège, Facebook page.

10 Literarily meaning "supports", this term is used by the members of the VSP to name those Belgian citizens who mobilize to help with the actions implemented by the VSP and that gather in what is called the "support committee". This group also mediate with institutional and other local actors when direct interlocution with undocumented migrants is precluded for several—logistic, strategic or constraining-reasons.

11 All names used for research participants are aliases.

12 However, the city later sold the buildings to a private owner. The occupants were not evicted, but relocation is needed urgently and is being negotiated as we write this article. 


\subsection{Claiming Existence}

The rights claiming process of the VSP (addressing human and civic rights, beside-and together with-regularization) is developed through concrete actions that testify to migrants' active role in the socio-cultural local life of the city. These actions consist of-among other things-working, attending school/classes (for children and adults), participating in creative workshops, protests and artistic productions. For their implementation, migrants can rely on the support of a network of actors including associations and NGOs working on migration issues, cultural associations, local services and institutions, political representatives, and individual mobilized citizens. The analysis of the actions of socio-cultural participation implemented by undocumented migrants leads to the emergence of a series of topics of which two are particularly relevant to the issues raised by this article. First, these activities are the locations where the performance of agency occurs despite structural constraints that individuals face due to their (il)legal statuses. The actions taken by migrants improve their daily lives and are a means of performing their struggle against the contemporary migration policies. However, we may question whether the spaces (and in particular the cultural spaces) in which migrants exert these actions are concrete locations for resistance or remain marginalized sites where migrants are again kept apart and whose exclusion is thus perpetuated with the alleged complicity of humanitarian aid. bell hooks proposes to solve this dilemma, to some extent, by making "a definite distinction between that marginality which is imposed by oppressive structures and that marginality one chooses as a site of resistance-as location of radical openness and possibility" (Hooks 1990, p. 153). Sociological marginality is transformed into rhetorical marginality (Gilbert 2004, p. 5), and this process enables us to put forward the subversive nature of migrants' actions (and in particular, as we will see below, of theatre practice). We assume, together with our research participants, that these actions convey a representation of undocumented migrants as active and autonomous subjects claiming their right to exist on Belgian soil:

"I was so upset when they said: 'oh poor people, poor people', it's always us the 'poor people'. When we are in need, we can ask for some help ... for me, help is necessary, but help must lead to freedom. Help cannot be permanent, help can lead to do without help. [ ... ] they want us to be dependent. [ ... ] actually, the fight of the sans-papiers has been taken in pincers [prise en tenaille, in French]". (Salim, recorded 30 January 2018)

We underline the importance of examining "to what extent arts are used and could be a useful tool in local incorporation" (Martiniello 2015, p. 1232), that is to "address the issue of incorporation of migrants from an uncommon perspective that also informs the process by which newcomers become-or do not-full members of a given society" (Martiniello 2015, p. 1233). In this case, arts constitute the basis of political action. It is through art practices that collective identities are positioned against the "local social and political order", thus playing a crucial role in social and political mobilization (Martiniello and Lafleur 2008; Mattern 1998)" (Martiniello 2015, p. 1233).

For the members of the VSP, arts are crucial to participation in the local socio-cultural life of the city and to their ability to claim civic rights. One of our research participants, a Belgian artist and worker within the domain of education, said: "with an artistic and cultural action they produce something that carries a meaning, that will resonate within a public" (Paul, recorded on 30 November 2017). Indeed, "artistic expressions can help build bridges to facilitate encounters (Vertovec 2007) between populations with different ethnic origins sharing the same city or the same neighbourhood" (Martiniello 2015, p. 1232), and this creates spaces for raising voices. The artistic activities of the VSP involved professional and non-professional artists, migrants and non-migrants, and these activities are considered art items because they were the result of a process of creation (Gell 1998). A series of writing, painting and theatre workshops were the origin of these art products. These workshops were locations for sharing experiences, expertise, thoughts, etc., among people with different stories and profiles, and where people could create art items to communicate these shared contents to those outside of the group. Among these art products were audio-visual creations shown within the framework of a 
local artistic event. During this festival, the owners of the villas in a middle-class neighborhood of the city of Liege opened the doors of their houses to artists (usually painters) who could then show and sell their works ${ }^{13}$. The members of the VSP, due to the intervention of a local resident, were able to use an uninhabited villa, owned by an institutional foundation, as the setting for their artistic productions. The first of these, located in the secondary entrance of the villa, was the installation of an audio-tape where one can listen to the life experiences of some members of the VSP (Figure 2).

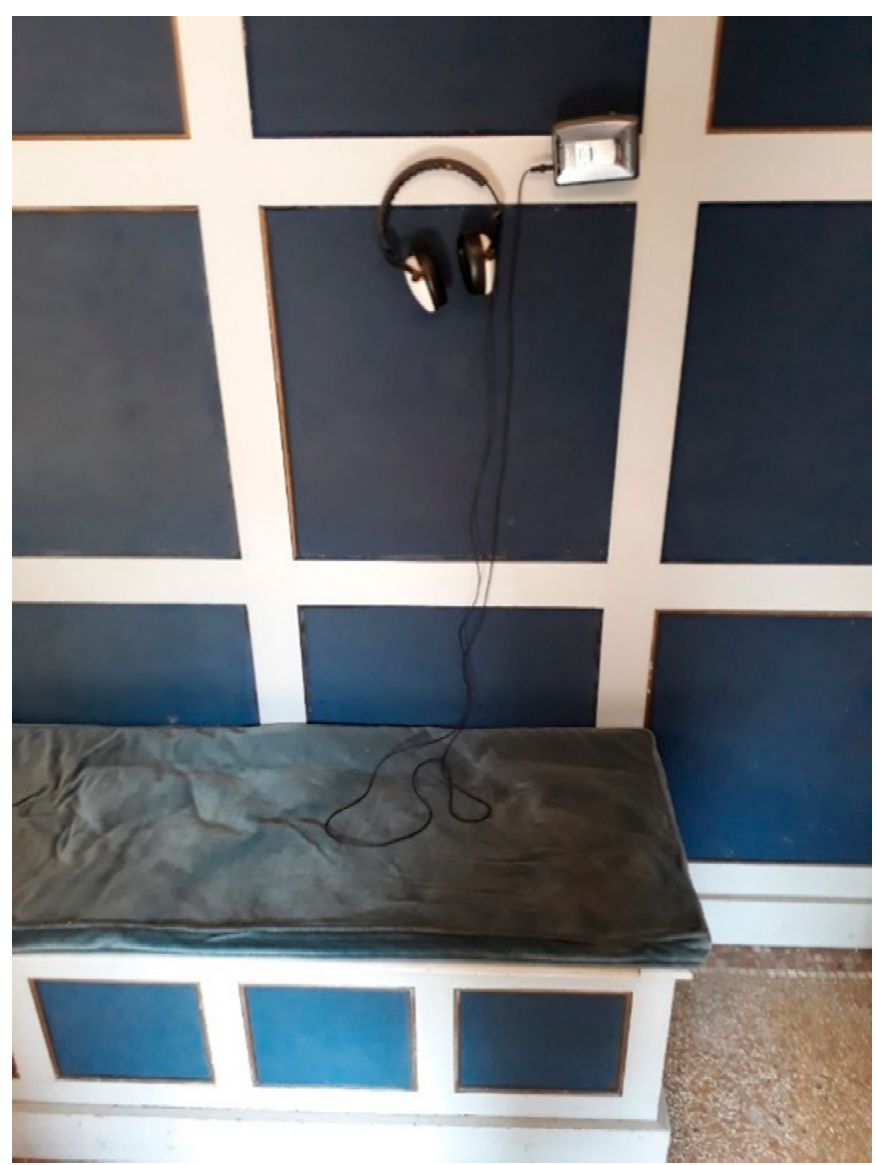

Figure 2. Installation at the Parcours d'artistes de Cointe, Liege, 20 May 2018 @ Elsa Mescoli.

Here is an excerpt of one woman's recording:

"I want to add something, some memories about Belgium, when I came, I was relieved, I thought I had found ... [ . . . ] where I had my rights, my freedom. But I was wrong, [ . . . ] after the negative answer [about refugee status request] I found myself as someone who has no right, no freedom, but I learnt with my family that you need to fight to go forward, I always fight to go forward, and I still have good memories. When I will have my rights, my freedom of saying what I think, my freedom of doing what I want, [ . . ] I always fight to have this. With the problems of not having documents, we learn how to help each other, [ ... ] we always have the hope ... ". (Fieldnotes, 20 May 2018)

Through narrating her migration experience, this woman describes the deception of the expectations that she had before leaving her country of origin as well as the motivations that push her to fight for her rights - the civic rights connected with receiving a residence permit through regularization.

13 Le parcours d'artistes à Cointe. 
Another room of the villa became the setting for representing thoughts on "vital space". Images of people lying on the floor showed how many persons could sleep (and live) in that uninhabited room. A text accompanied the installation:

"Life becomes for oneself as a globe that turns around itself. In this world, everyone must live without obstructing the life of the others. In this world, there are so many people that live in an incredible precariousness, and all this is caused by the others' wickedness. In this world, and more precisely in Belgium, there exist people, migrants, men, women, children, in illegal situation, called sans-papiers, that struggle to find a vital space". (Idem.)

In the garden, a tree was decorated with some "questions without answers" (Figure 3a), such as:

"Why so little sharing of our richness? Why so little welcome to men and women that escape from their countries because they are hungry, because they are persecuted? Why Belgium does not give papers? Why isn't there free circulation of people? Why seven years in Belgium without documents? Why I miss my family? Why and how will we put things in order in this unfair world? How can we live together? To whom asking help? To what all this is useful? How to get out of this suffering? Where do we go after this long struggle? When and how the end will come?". (Idem.)

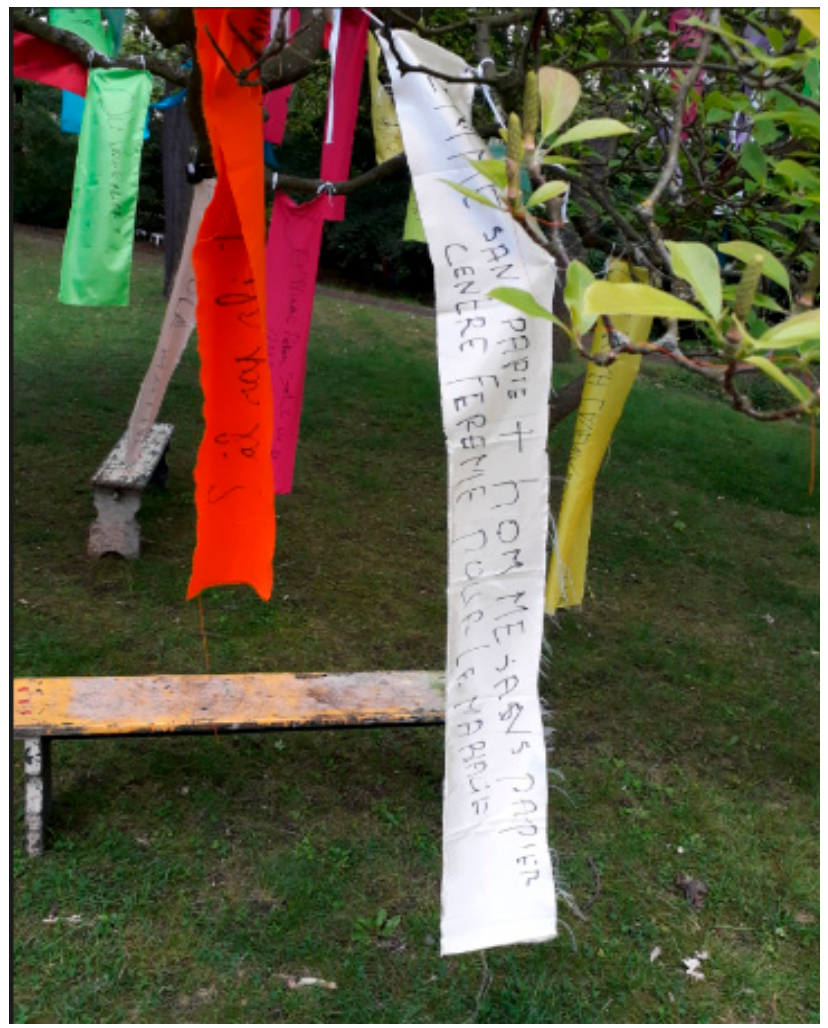

(a)

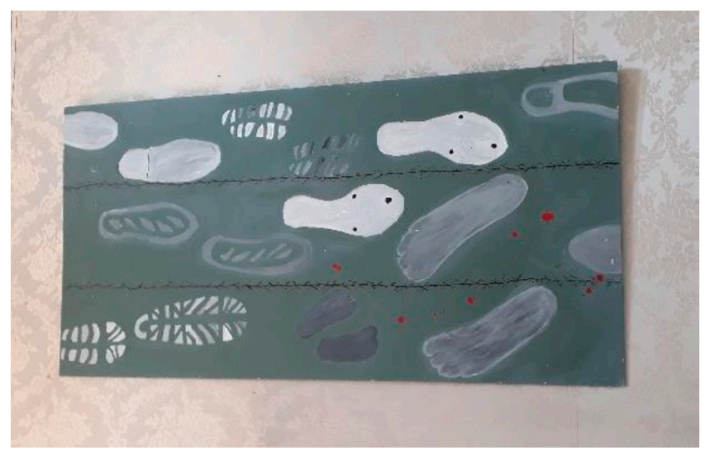

(b)

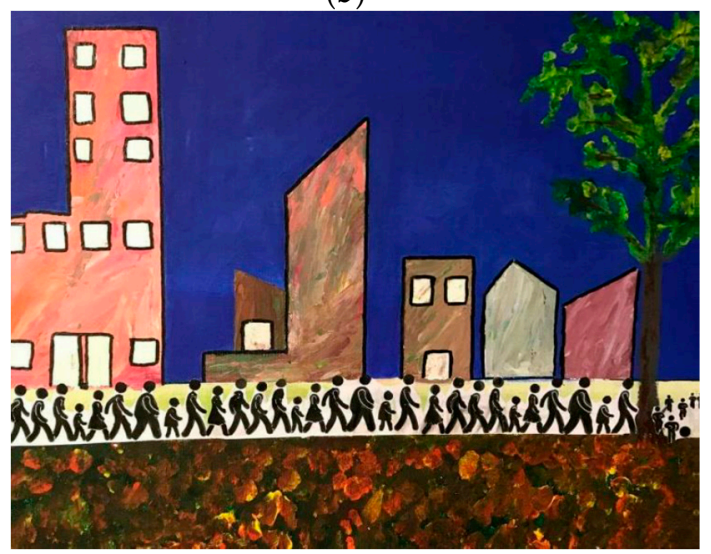

(c)

Figure 3. The tree of the "questions without answers" (a) and some paintings of the collective (b,c), Parcours d'artistes de Cointe, 20 May 2018 (C) Elsa Mescoli and La Voix des Sans-Papiers de Liège, used with permission.

Some paintings depicted "the path of a migrant: the departure, the ghosts, the hopes; the journey, the path of difficulties; distance, absence, roots, wandering" (idem, Figure 3b,c).

Some members of the VSP also participated in a project that the Theatre of Liege implemented with the aim of fighting discrimination through arts. Some theatre workshops trained the bodies and the gazes of the participants (here, undocumented migrants, actors, and local students) to move within 
a shared space and to coordinate movements with others by interacting with them visually and bodily. After this exercise, the focus was on the practice of the clown, an artistic way to become other than oneself and to experience alterity (or one's own experience through the gaze of a dissociated-self) ${ }^{14}$. We can read in this excerpt of a dialogue between the professional actor leading the workshop and one of the participants on how this artistic performance conveyed meaning related to being sans-papiers:

- $\quad$ Do you have something to say?

- $\quad$ I am tired.

- Why are you tired Toni?

- I am illegal in Belgium.

- Explain me.

- I am a sans-papiers.

- $\quad$ OK, so this [the nose] is the symbol of sans-papiers? (Fieldnotes, 30 March 2018).

During this and several other similar moments of performance, the effects of illegality on everyday life were brought to the scene. In fact, an intrinsic relationship connects theatre with reality (Beeman 1993, p. 372, referring to Schechner 1985). However, the context of the performances is governed by rules that are different from those governing everyday actions. Rituals to become other than himself/herself accompany the practice of the clown. Before starting the performance, the actor needs to embody his or her character with a series of actions focused on the body:

"Breathe deeply from your nose, close your eyes, and as a puppet, we cut the threads [the actor sitting on a chair leaves his/her arms and bust fall to the floor]. When you are completely relaxed, you wear the nose [ ... ]. You lift your head with your eyes closed, and when you open your eyes, everything will be possible, except what is normal". (Fieldnotes, 26 April 2018) ${ }^{15}$

Once on the stage, the new character (the clown) can reverse hierarchies and power dynamics through capitalizing on difference and stigma as evidence of existence. As Goffman puts it, the humor of the stigmatized makes him a "half-hero" who "is made to guilelessly outwit a normal of imposing status" (Goffman 2009, p. 108). Some individuals, who are legally excluded from the society, create places where they can perform their life and find their voice through artistic performance. Through humor in particular, the artist can express a social critique (Gilbert 2004), thus re-positioning her or himself as an active actor in the society. From this position, undocumented migrants re-acquire a degree of freedom in a social space where the borders of social categories fade. The performance of subordination and marginalization gives visibility to these processes and to the status that derives from them.

On other occasions, however, the topics connected with the issue of illegality were not directly mentioned and it seemed that the aesthetic scope of the activity prevailed. In fact, art performance was also an end in itself. It offered possibilities to engage in a cultural activity, to spend time with people, and to find some way to belong.

The audiences of these artistic projects were different in the two examples mentioned above. In the first case, the described festival is an open event attended by any individual who may be generally interested in arts and not necessarily in migration issues. People visiting the villas because of their artistic interests almost casually came across the artistic products realized by the VSP and thus the contents that these products conveyed-notably, of claiming regularization and the civic rights that derive from it. Unexpected discussions on these topics emerged among unaware observers. Concerning the theatre workshop, the first meetings that are described here did not yet imply the

14 On the role of theatre and humor for marginalized categories of people (including a gender approach), see Gilbert (2004).

15 These words are from the professional actor guiding the theatre workshops. 
participation of the public since they were more like training sessions. However, some spectators were almost always present and they included, besides the researcher who observed the workshop, members of the theatre and other people who supported the activities of the VSP. The variation of the public in terms of its composition and scope did not necessarily impact the effect of the performances. In fact, in all the described cases, the performances reached an audience and in doing so, they triggered discussion on migration issues and they brought migrants into visible action. The artistic activities of the VSP are renowned locally as well as beyond the territory of Liege, since at least two of the theatre plays that they created are regularly performed in different locations in Belgium. The political scope of these artistic initiatives is evident: these actions are intentionally aimed at giving visibility to undocumented migrants and stating the need of regularization procedures that would enable the recognition of their legitimate and legal existence in the country.

\section{Arts to Be Invisible}

\subsection{Superdiverse Brussels}

Clear in the above examples is that art is regularly and effectively used as a form of protest, a way of highlighting issues, calling for change, and sharing one's own unique position and struggles with a wider audience. Some artists, however, want to simply be labeled as artists and do 'art for the sake of art' or indeed participate in the arts to build community and find a sense of 'belonging'. Brussels, unarguably a superdiverse (Vertovec 2007) city with a long immigration history and a prominent place on the international political stage, is a place where one can choose to be highly visible or almost entirely invisible. Brussels as a city has some unique characteristics that set it apart from other major metropoles/global cities. As of 1 January 2018, the population of the Brussels Capital Region was $1,198,726$. The number of people with nationalities from the 28 European Union member states (and not also having Belgian nationality) was 276,098 and third-country nationals was 141,00916. In 2015, the immigrant and foreign-born population accounted for $62 \%$ of the total population of the city, coming in second to Dubai which, at $83 \%$, had the highest percentage of immigrant foreign-born population in a city (International Organization for Migration 2015). In addition to hosting numerous European and international institutions and the workforce that comes with them, Belgium also receives a significant number of refugees and asylum seekers. Their situation in Brussels has sometimes garnered international attention, with, at various times, hundreds of asylum seekers queuing outside the Foreigners Office and sleeping in the park across the street. When hundreds of rejected Afghan asylum seekers sought asylum in a Brussels church, it remained a regular story in local and international news for several months (Willner-Reid 2015). Brussels, under the spotlight brought by international and EU institutions, has the same struggles as many other cities when it comes to the politics of accepting refugees and granting asylum and how people are cared for while their situations are unsettled. Against this backdrop, Brussels fancies itself an artistic city, having attracted a large number of artists despite the competition of larger cities with thriving art communities, such as Paris, nearby. Brussels has a large number of exhibits and artistic initiatives, often with the focus of depicting the city and local interpretations of the urban environment (Reverseau 2019). These depictions and reimaginings are created by anyone having ties to the city and national belongings rarely factor in, and, as Costanzo and Zibouh state, arts can create a space for "a certain affirmation of an identity that, in this case, transcends prescribed ethnic and migrant identities and attempts to establish a new means of self-assertion in the post-migration context by promoting a place-based (Bruxellois) identity" (Costanzo and Zibouh 2014, p. 56).

$16 \mathrm{https} / /$ statbel.fgov.be/en/themes/population/structure-population\#panel-12. 


\subsection{Music Groups as Sanctuaries: The Case of Undocumented Migrants in a Brussels Church}

In Brussels, there are numerous organizations and groups rallying for the rights of undocumented migrants either as their main mission or in addition to other activities. In 2013, a group of hundreds of rejected asylum seekers from Afghanistan were offered sanctuary in a Brussels church. Initially, this event was widely covered in the media and there were regular protests that garnered significant community support. According to Eurostat, more than 20,000 Afghans sought asylum in the European Union in 2013, and approximately 1300 applied in Belgium (Bitoulas 2014). Public outcry was partially to thank for the subsequent actions of the office of Maggie De Block, who in 2014 was the Minister of Justice charged with Asylum, Immigration, Social Integration, and Poverty Reduction in the Di Rupo Government. Her office asked the failed asylum seekers to reapply for asylum. The majority of the group from the church decided to go ahead with these procedures which meant that they were allowed to live in the centers that are provided for asylum seekers while they awaited the outcome of their applications. As a result, most of the Afghans left the church by February 2014 (Willner-Reid 2015, p. 514). The Afghans who remained in the church in January to June 2015, when fieldwork was conducted, were mostly single men in their 20s and 30s-those who felt that they would have their applications for asylum rejected upon resubmission and thus be deported.

The church remained open at this time and served as the 'Afghan info point' where anyone could walk in during the day and read posters created by the undocumented residents to learn about their situation (Figure 4). In fact, it was also possible to simply walk up to the residents and inquire about their situation. Even though media attention had abated, the situation of the Afghans in the church still enjoyed great local notoriety. They were still incredibly 'visible' even if it seemed that the city was no longer paying attention to their plight. One former resident of the church, Amir, stopped living there when he was offered a room in a friend's house. Life in the church clearly revolved around the regular protest marches and political actions of the group (Figure 5). He said he came back to the church often to visit his friends, but he appreciated being able to focus on other parts of his life.

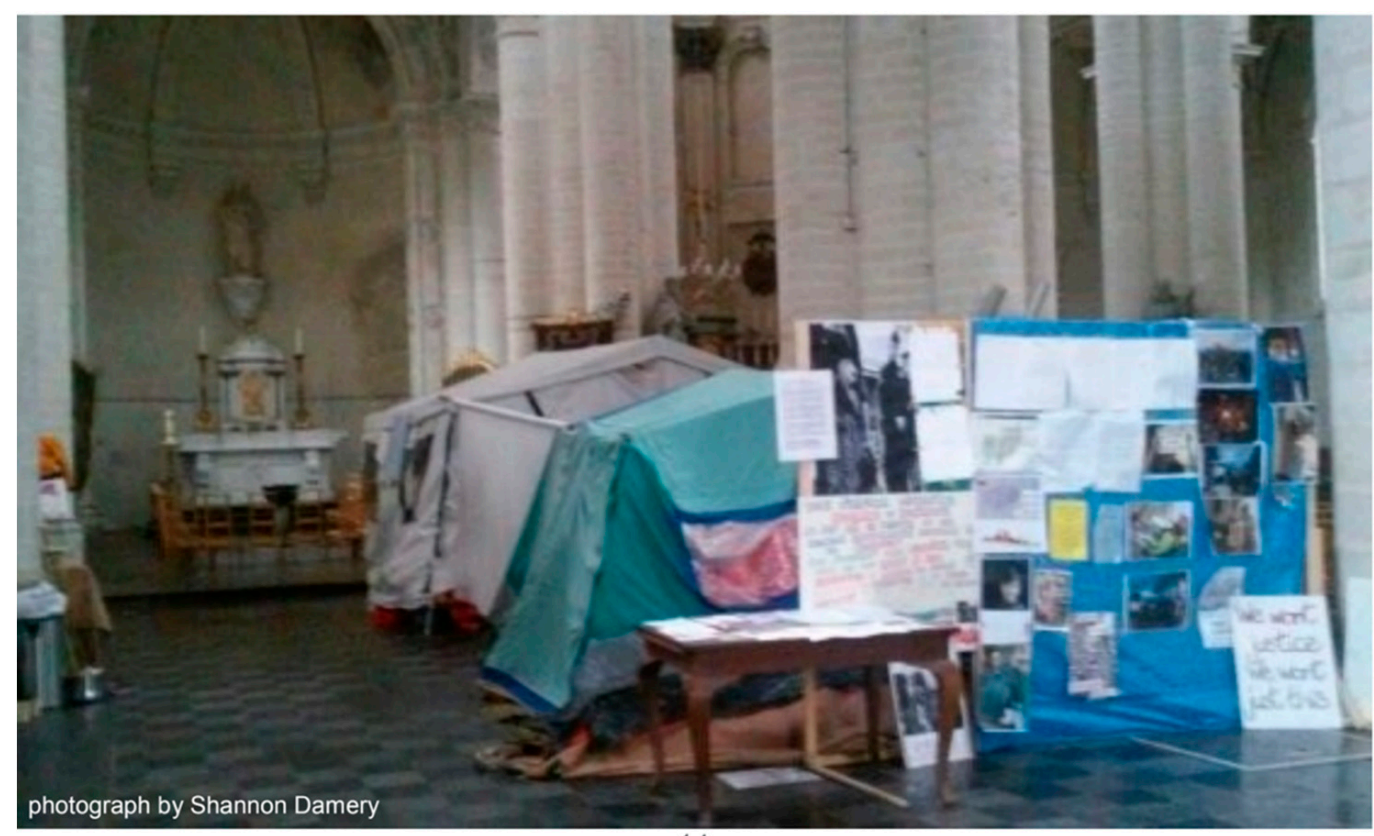

Figure 4. Inside the church. 15 January 2015 @ Shannon Damery. 


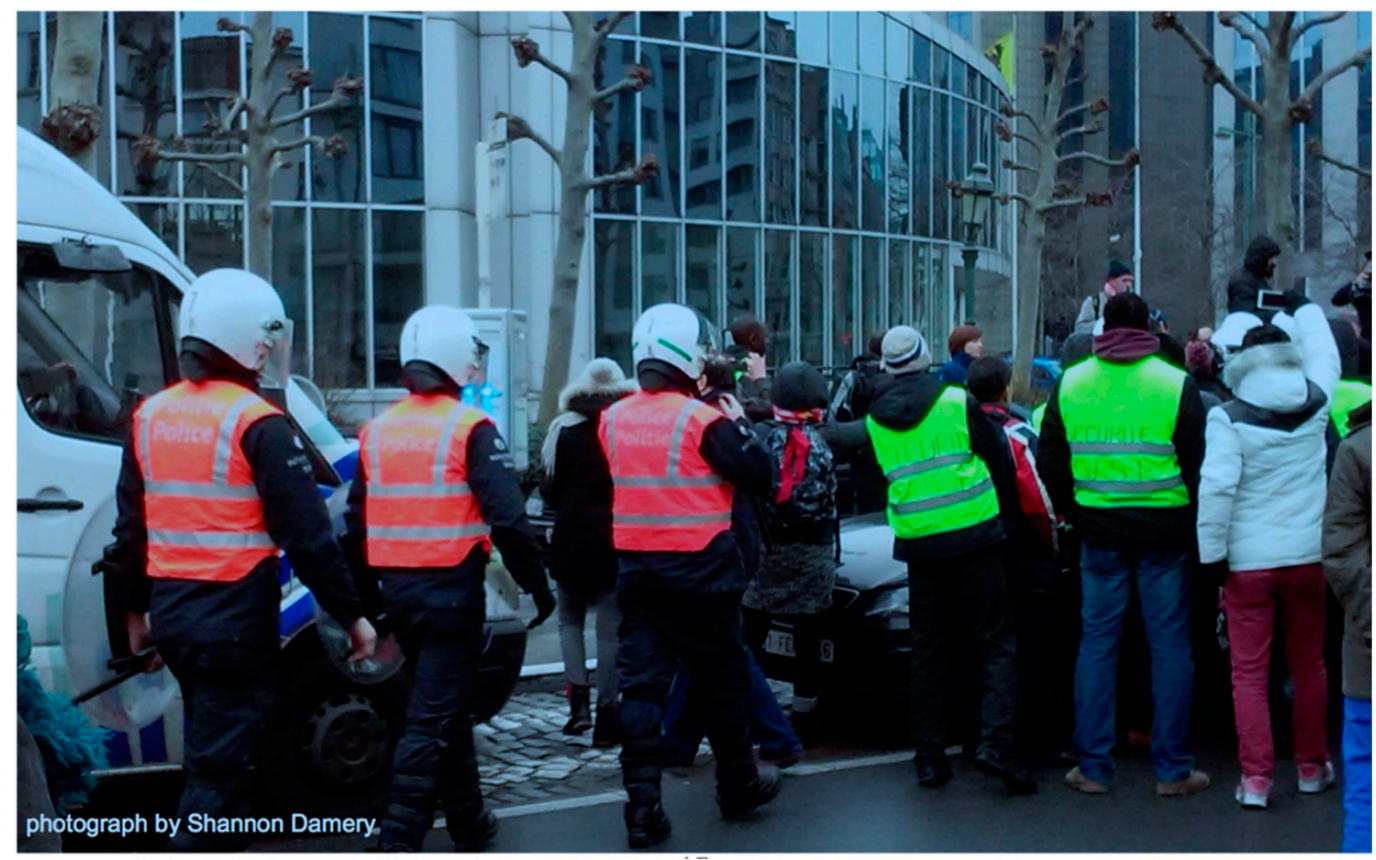

Figure 5. Police and 'sans papiers security' at a manifestation in Brussels. 4 March 2015 @ Shannon Damery.

He decided to dedicate some of his time to a music group of undocumented people, but this was not his first choice. There are places in Brussels specifically for immigrant artists to practice their work, one of which will be described in greater detail in the following example, but Amir wanted to join a music group in The Centre for Fine Arts in Brussels (BOZAR). He found this was impossible without being able to show some kind of identification. As Martiniello (2015) stresses, arts can be a vehicle for gaining attention for a platform, and it can also be a tool for incorporation and building bridges between cultures. Sometimes, however, as was the case with Amir, these are two separate aims. Amir wished, at least in the artistic part of his life, to be connected with Belgian society but not necessarily to be part of a highly visible platform for a political aim.

In her study, Rotas (2012) explains how refugees helped to change the category of British art and what it means to be British. She gives an account of refugee artists whose work was displayed in an exhibition of British art. While Rotas tells us that the cultural grounding of the artwork is still very clear, and the audience is aware that the works represent cultural experiences they have not encountered or do not understand, cultural transmission is still occurring and the host culture is being influenced (Rotas 2012, p. 212). Rotas further explains that the definition of the refugee's work as 'British' contributes to the remaking of "place Britain" and the idea of Britishness (Rotas 2012, p. 219). If these works had been displayed in an exhibition of immigrant art, for example, the work would have been cast in a different light and the audience invited to focus on differences. As it stands, the refugees gained unofficial status as 'British' in a significant type of acceptance into the community. It is important to note that these groups, as useful and well-intentioned as they are, may still serve to separate migrants from the wider society. Amir ultimately joined a group of undocumented musicians where the teacher did not ask for identification. He seemed to appreciate this group and find through it some type of belonging, in the way described by May (2013). Amir said that the people in the group were all from different countries and that their singing together was "like a solidarity action" (interview, 16 February 2015). This is similar to May's explanation that, "music can also form part of collective experience and identity, as evidence whenever Liverpool Football Club fans sing 'You'll never walk alone'" (May 2013, p. 135). This action and group, however, still did not have the aim of promoting a common political cause of the participants and making their particular situation more visible. Roy and Dowd explain that groups "use music as a tool for building identity—an 'us' (Roy 2002) The relationship between a group and music flows two ways: Music is identified by people 
inside (and out-side) the group as belonging to it, and membership in the group is marked partly by embracing this music" (Roy and Dowd 2010, p. 190). In many cases, it seems that people wish to somehow 'disappear into belonging' and become less visible by being part of a group with less politically or cause driven aims.

\subsection{Belonging without Politics? The Case of the Roma Music Group}

Another example of this phenomenon was a music group based in a cultural centre in Brussels. The aim of the group itself was to make visible a group of people and a political aim. The centre was a non-profit funded in part by Flemish cultural initiatives. It provided a place and materials for refugees and asylum-seeking artists to practice their art. In addition to supporting these artists, the organization also spoke about encouraging discussion around social issues since the international make-up of Brussels makes it ripe for such dialogue. As part of a collaborative effort with other organizations, the centre created a musical group that for the purposes of this article will be called The Balkan Review. The specific aims of the review were to promote the inclusion and positive image of the Roma community in Europe, and may be linked to an increased interest from EU bodies to promote Roma inclusion across EU member states. The review made certain to include Roma and non-Roma musicians and directors and seemed to pride itself on the fact that it was initiated by a Roma organization.

The project is still ongoing, and the website described the aims of the project in the following way:

With this project, [org. name] aims to generate more insight and understanding for the large Roma immigration from the Balkans to more economically successful countries like the Netherlands, Belgium and Germany. Only when you know why they came here and what the position of the Roma in their home countries is, can you properly understand the immigration of Roma. (... ) The fact that this project is also supported and initiated by the Roma community, which heretofore was seen as a closed off community, makes this project remarkable.

Because members were often coming and going, it is impossible to say exactly how many members of the Brussels Balkan Review there actually were and from which backgrounds, but in addition to Roma members, there were people from many immigrant, non-immigrant, European and non-European backgrounds.

The organizers and funders of the group had more specific aims and stronger opinions than the performers on the identities they were promoting, what kind of 'integration' they wanted to foster, and the audience they wanted to reach. They were hoping to promote the inclusion of Roma youth in Belgium seemingly by reaching a non-Roma audience of 'locals'. The venues included schools, cultural organizations, and a large concert hall in Antwerp. The performers and director, however, cared about the music they were producing above all else. All of the young people said that they came because they liked the group and had fun, and because their friends came. One participant from the Balkan region said that he came because he liked playing music he used to play with his family. Another participant, who was undocumented, joined the group simply to be with his friends and learn other languages. He said that he was involved in a lot of political actions but the music group was just for fun (fieldnotes, 22 March 2015). As stated above, the arts are connected to feelings of nostalgia, but Baily suggests that music may also offer a feeling of security.

... the primary effect of music is to give the listener a feeling of security, for it symbolizes the place where he was born, his earliest childhood satisfactions, his religious experience, his pleasure in community doings, his courtship and his work-any or all of these personality-shaping experiences. (Baily 1999, p. 11)

In both the rehearsing and performing, it seemed that the participants felt a sense of security in their belonging to the group. Even for the researcher, who was not familiar with the songs and types of 
music the group performed, the practice of performing together in the group brought back memories of performing in choirs in the past. There was also no concern from the undocumented members of the group that the audiences might not be receptive or that there would be a lack of acceptance. The audiences who attended the concerts did appear to be quite mixed with many different languages being spoken, but a large portion of each audience were the friends and family of the performers, so it remains unclear if the organization reached its intended audience. In any case, the performances were always met with enthusiasm from the audience-the bigger concerts seeing people getting up and dancing to the music, some who knew the 'traditional dances' and some who clearly did not.

The group could be divided along several different lines, and one of these was between members from the Balkans and those who were not. While this division, and others, were important, it was also important that there was group cohesion built around the performing of these songs and in everyone becoming familiar with and appreciating the music. Having a good performance took precedence over the aim of promoting Roma culture, which was still a result of project, but not the main aim of the participants. Martiniello (2018) noted the emergence of post-racial groups among young artists in Belgium stating that young people growing up in multi-cultural, diverse environments see this as a simple fact of life and when engaging in artistic practices; the outcome of the art project is the main focus.

"I call this urban generation post-racial not because they have become colour-blind but because the traditional forms of categorization (racial, ethnic, gender, class, etc.) seem to lose salience in their daily peer group inter- actions. Their ethnic and racial identification do not orient the forms of inter-action and cooperation they develop with other urban youngsters. The shared artistic project is much more important than their alleged ethnic or racial identity". (Martiniello 2018, p. 1153)

This idea is significant when looking at immigrant artists who do not wish to be seen as 'other', and wish to 'disappear' into a group where their belonging is not questioned and they do not have to be part of a particular political aim.

\section{Concluding Remarks}

These examples enable us to state that, in spite of structural constraints, art is a means (and a product) through which migrants, independent from their legal status, participate in the local socio-cultural life and elaborate concrete claims concerning their own situation as well as global concerns that are related to it-such as migration governance and politics. Art practice constitutes a creative political engagement in the local context (Salzbrunn 2014) and also a way for people to find belonging without caveats (Martiniello 2018). In Belgium, the contemporary climate on migration reflects the debates spreading at the European level. The situation is particularly difficult due to the restrictive policies and practices adopted by the former right-wing Secretary of State in charge of these affairs at the federal level ${ }^{17}$. The local environments (cities) can constitute spaces of resistance to the overall politics, in which migrants who are made invisible by the rejection of their demands for regularization and the denial of their existence on Belgian soil, become visible through concrete actions. Legitimating their presence and action in the public space in spite of their legal status permits the blurring of the boundaries between illegality and legality. Culture and artistic practices in post-migration urban settings emerge here as tools to promote social cohesion and integration through the action of formal and informal networks (Clavier and Kauppinen 2014; Vanderwaeren 2014) involving a variety of social profiles of which migrants—and in our case, undocumented migrants in particular-are a part.

17 Theo Francken, Nieuw-Vlaamse Alliantie (N-VA). No relevant changes, as far as the approach to migration issues is concerned, occurred in spite of his recent resignation and his replacement by Maggie De Block, Open VLD, already mentioned above in this article. 
Participation in arts practices can result in the blurring of divisions between people of different backgrounds and migratory statuses. This is precisely what makes the arts a way for migrants to become 'invisible' by finding unofficial acceptance in a host society. Indeed, we saw how art practice is not only a means, but also an end in itself. It constitutes an aesthetic and corporeal device that undocumented migrants can, and do, experience in positive terms. Art is a vehicle through which our participants activated their agency in order to claim belonging in Belgium despite their status as undocumented or 'other', by making themselves and their situation more visible or by choosing to, at least temporarily, leave their classification of being 'other' behind and merging seamlessly into an arts group. While the intention of the artists here is key, this is often a difficult aspect to unravel and fully understand. Long-term engagement in arts projects through participant observation allowed us to better understand this dimension, but there are still subtleties that were perhaps less apparent and intention is incredibly nuanced. Research in this domain undoubtedly profits from employing participatory and co-creation methods, and future research would benefit from a better understanding of the impact of audience reactions to artists' endeavors to find belonging, either through increased or decreased visibility.

Author Contributions: E.M. wrote the sections concerning the artistic practices developed by migrants in the city of Liege, while S.D. wrote the sections concerning the artistic practices developed by migrants in the city of Brussels. Both authors wrote all the other sections (Introduction, Methodology, Concluding Remarks).

Funding: Belgian Federal Science Policy Office (BELSPO), funding agency of the project "Public opinion, mobilisations and policies concerning asylum seekers and refugees in anti-immigrant times (Europe and Belgium)" (PUMOMIG). Elsa Mescoli collected the ethnographic material presented in this paper and concerning migrants' action in the city of Liege within the framework of this project. The researched conducted by Shannon Damery received funding from the European Union's Seventh Framework Programme (FP7/2007-2013) under grant agreement $n^{\circ} 316796$. She gathered the materials in this article thanks to funding as a fellow in the Marie Curie Initial Training Network.

Acknowledgments: We thank all the artists mentioned directly or indirectly in this article that let us explore and participate in their art practice, and all other migrants that were involved in the research connected with the material presented here.

Conflicts of Interest: The authors declare no conflict of interest.

\section{References}

Baily, John. 1999. Music and refugee lives: Afghans in Eastern Iran and California. Forced Migration Review 6: 10-12.

Baily, John, and Michael Collyer. 2006. Introduction: Music and migration. Journal of Ethnic and Migration Studies 32: 167-82. [CrossRef]

Becker, Howard. 1982. Art Worlds. Berkeley: University of California Press.

Beeman, William O. 1993. The anthropology of theater and spectacle. Annual Review of Anthropology 22: 369-93. [CrossRef]

Bertholet, Edith Dieng, Honoré Abdourahmane Ndayishimiye, and Elsa Mescoli. 2018. La création dans l'inconfort: L'expérience théâtrale pour et par les migrants sans-papiers de Liège. Paper and video presented at the Conference: Migrations: nos voix, nos chemins de traverse rencontre entre arts, sciences et militances, Marseille, France, October 25.

Bitoulas, Alexandros. 2014. Eurostat Data in Focus: Population and Social Conditions (Published online March 2014). Available online: http:/ / ec.europa.eu/eurostat/documents/4168041/5948933/KS-QA-14-003-EN. PDF/3309ae42-431c-42d7-99a3-534ed5b93294 (accessed on 1 December 2017).

Bousetta, Hassan, Lafleur Jean-Michel, and Gregor Stangherlin. 2018. Ville multi-inter-culturelle? Discours, pratiques, réalités. In Regards sur la ville. Echanges et réflexions à partir de Liège. Edited by Brahy Rachel, Dumont Elisabeth, Fontaine Pierre and Christine Ruelle. Liège: Presses Universitaires de Liège, pp. 69-89.

Clavier, Berndt, and Asko Kauppinen. 2014. Art for integration: Political rationalities and technologies of governmentalisation in the city of Malmö. Identities 21: 10-25. [CrossRef]

Costanzo, Joseph, and Fatima Zibouh. 2014. Mobilisation strategies of individual and institutional actors in Brussels' artistic and cultural scenes. Identities 21: 42-59. [CrossRef] 
De Genova, Nicholas P. 2002. Migrant “illegality" and deportability in everyday life. Annual Review of Anthropology 31: 419-47. [CrossRef]

DiMaggio, Paul, and Patricia Fernández-Kelly. 2015. Immigration and the arts: A theoretical inquiry. Ethnic and Racial Studies 38: 1236-44. [CrossRef]

Elias, Nelly, Lemish Dafna, and Natalia Khvorostianov. 2011. Britney Spears Remained in Russia: Dynamics of Musical Preferences in the Integration of Immigrant Adolescents. Journal of Ethnic and Migration Studies 37: 61-77. [CrossRef]

Emerson, Robert, Fretz Rachel, and Linda Shaw. 2001. Participant Observation and Fieldnotes. In Handbook of Ethnography. Edited by Paul Atkinson, Amanda Coffey, Sara Delamont, John Lofland and Lyn Lofland. London: Sage Publications Ltd., pp. 352-68.

Gell, Alfred. 1998. Art and Agency: An Anthropological Theory. Oxford: Clarendon Press.

Gilbert, Joanne R. 2004. Performing Marginality: Humor, Gender, and Cultural Critique. Detroit: Wayne State University Press.

Goffman, Erving. 2009. Stigma: Notes on the Management of Spoiled Identity. New York: Simon and Schuster.

Harrell-Bond, Barbara E. 1986. Imposing Aid: Emergency Assistance to Refugees. Oxford: Oxford University Press.

Hooks, Bell. 1990. Yearning: Race, Gender and Cultural Politics. South End: Bell Hooks.

International Organization for Migration. 2015. World Migration Report 2015-Migrants and Cities: New Partnerships to Manage Mobility. Geneva: IOM, Available online: http:/ / publications.iom.int/system/files/wmr2015_en. pdf (accessed on 13 February 2019).

Martiniello, Marco. 2011. La démocratie Multiculturelle, Citoyenneté, Diversité, Justice Sociale. Paris: Presses de Sciences Po/La Bibliothèque du citoyen.

Martiniello, Marco. 2015. Immigrants, ethnicized minorities and the arts: a relatively neglected research area. Ethnic and Racial Studies 38: 1229-35. [CrossRef]

Martiniello, Marco. 2018. Local communities of artistic practices and the slow emergence of a "post-racial" generation. Ethnic and Racial Studies 41: 1146-62. [CrossRef]

Martiniello, Marco, and Jean-Michel Lafleur. 2008. 'Ethnic Minorities' Cultural Practices as Forms of Political Expression: A Review of the Literature and a Theoretical discussion on Music. Journal of Ethnic and Migration Studies 34: 1191-15. [CrossRef]

Martiniello, Marco, and Jean-Michel Lafleur. 2010. Si se peude! Music, Musicians and Latino Vote at the 2008 US Presidential Election. Migracões 7: 213-29.

Mattern, Mark. 1998. Acting in Concert. Music, Community, and Political Action. New Brunswick: Rutgers University Press.

May, Vanessa. 2013. Connecting Self to Society: Belonging in a Changing World. Hampshire: Palgrave Macmillan.

O'Neill, Maggie. 2008. Transnational refugees: The transformative role of art? Forum: Qualitative Sozialforschung/ Forum: Qualitative Social Research 9: 59.

Pink, Sarah. 2009. Doing Sensory Ethnography. London: Sage Publications Ltd.

Reverseau, Anne. 2019. Presenting a city: Brussels and its subjective portraits. Brussels Studies [Online], General Collection, 132. Available online: http:/ /journals.openedition.org/brussels/2407 (accessed on 13 February 2019). [CrossRef]

Rose, Tricia. 1991. "Fear of a Black Planet": Rap Music and Black Cultural Politics in the 1990s. Journal of Negro Education 60: 276-90. [CrossRef]

Rotas, Alex. 2012. From 'asylum-seeker' to 'British artist': How refugee artists are redefining British art. Immigrants and Minorities 30: 211-38. [CrossRef]

Roy, William. 2010. How Social Movements Do Culture. International Journal of Political and Cultural Sociology 23: 85-98. [CrossRef]

Roy, William G., and Timothy J. Dowd. 2010. What is Sociological about Music? Annual Review of Sociology 36: 183-203. [CrossRef]

Salzbrunn, Monika. 2014. How diverse is Cologne carnival? How migrants appropriate popular art spaces. Identities 21: 92-106. [CrossRef]

Schechner, Richard. 1985. Between Theater and Anthropology. Philadelphia: University of Pennsylvania Press.

Street, John. 2003. 'Fight the Power': The Politics of Music and the Music of Politics. Government and Opposition 38: 113-30. [CrossRef] 
Tacchi, Jo. 1998. Radio Texture: Between Self and Others. In Material Cultures: Why Some Things Matter. Edited by Daniel Miller. London: University College London Press, pp. 25-46.

Vanderwaeren, Els. 2014. Integrating by means of art? Expressions of cultural hybridisations in the city of Antwerp. Identities 21: 60-74. [CrossRef]

Vertovec, Steven. 2007. Super-diversity and its implications. Ethnic and Racial Studies 30: 1024-54. [CrossRef] Willner-Reid, Matthew. 2015. Emergence and Decline of a Protest Movement: The Anti- Deportation Campaign for Afghan Asylum Seekers in Belgium. Journal of Refugee Studies 28: 505-22. [CrossRef] 